\title{
Transformation of the EFQM approach from business towards operations excellence
}

\author{
Andreas Jaeger ${ }^{1,2} \cdot$ Kurt Matyas ${ }^{2}$
}

Received: 1 November 2015/ Accepted: 9 February 2016/Published online: 22 February 2016

(C) The Author(s) 2016. This article is published with open access at Springerlink.com

\begin{abstract}
The purpose of this paper is to provide an enabler-based approach for a supervised self-assessment of operations excellence (OsE). Based on the latest approaches of excellence in operations from the literature as well as on the philosophy of the EFQM model, an OsE working definition was developed. In contrast to operational excellence (OE), which deals exclusively with the optimization of result driven processes, OsE promotes the enhancement of operation-specific enablers and linked results. The evaluation of crucial cause-effect relationships of relevant enabler and result criteria supports the determination of a company's capability to achieve sustainability and excellence in terms of its operations. To foster a methodical integration of OsE in organizations, a phase model for a systematic assessment process was designed and verified with 24 companies in the Austrian machinery and metalware industries.
\end{abstract}

Keywords Operations excellence $\cdot$ Operational excellence $\cdot$ EFQM $\cdot$ Performance measurement $\cdot$ Selfassessment $\cdot$ Enablers

\section{Introduction}

As markets become more accessible in an increasingly global world, companies aspire towards excellence to ensure their ongoing competiveness. Market conditions

Andreas Jaeger

andreas.jaeger@fraunhofer.at

1 Fraunhofer Austria Research GmbH, Theresianumgasse 27, 1040 Vienna, Austria

2 Vienna University of Technology, Theresianumgasse 27, 1040 Vienna, Austria force organizations to not only respond to prevailing challenges but also seek long-term success by achieving excellence in their business. Organizations that exhibit business excellence develop organizational capabilities in order to manage change and its consequences effectively. In the field of operations management, organizations can increase their competitive position by using tools, methods, concepts and technologies [1]. From the perspective of the operations level, the definition of excellence is nebulous and continually so in experts' discussions. Furthermore, it is unclear, how to measure an individual company's excellence in operations. "Assessing excellence is an essential part of learning and a measurement process, which involves people in self-assessment and allows organizations to identify strengths and improvement opportunities as well as enabling the progress of excellence programs to be monitored in a systematic way." [2]. Therefore, this paper elaborates on the definition and the assessment of operations excellence by combining theoretical and practical research.

The following research is started with a review of key literature (Sect. 2) in the field of operational and operations excellence to create a more thorough understanding of these terms. Relating to consolidated findings, a working definition of operations excellence is developed (Sect. 3) to provide a fundamental basis for the assessment of excellence in operations. In Sect. 4, arguments are raised why the EFQM model for business excellence is useful but has to be partly adapted to evaluate operations excellence. Further steps focus on the detailed composition of an operations excellence assessment itself. The first step involves the setting of a model framework (Sect. 5). Then, an assessment phase model is defined (Sect. 6) in order to provide a methodology for applying the model framework. Section 7 summarizes the case studies for validating the 
developed operations excellence self-assessment. Finally, conclusions are drawn with a discussion of gained research results and with a view towards potential future research.

\section{Trend from operational excellence to operations excellence}

In recent years, a paradigm shift from operational excellence $(\mathrm{OE})$ to operations excellence (OsE) was observed. Porter's [3] generic value chain is used to identify the role, position, and interaction of $\mathrm{OsE}$ and $\mathrm{OE}$ in industrial companies. Figure 1 shows that Business Excellence addresses all aspects of the entire organization [4]. Operational excellence (OE) predominantly deals with the efficiency (e.g., productivity) and optimization of the process of transforming various resources (input) into valueadded products or services (output). Such an exclusive view means that $\mathrm{OE}$ tends to pay much attention to processes and their outcomes, e.g., lead time and price [5]. However, organizations are not totally process-driven but rather may be a combination of functions, technologies, behaviors, enablers [6], and processes.

In comparison, operations excellence (OsE), at a detailed level within the excellence approach in operations, represents the subsystem of the organization concerned with the aptitude of production and logistics as well as related administration. It broadens the view of operations as a setting lever by providing particularly (but not only) intangible enablers with a central role for operational longterm success.

The growing attention paid to $\mathrm{OE}$ in the literature can be categorized into four interrelated streams: OE 1.0, OE 2.0, OE 3.0, and OE 4.0.

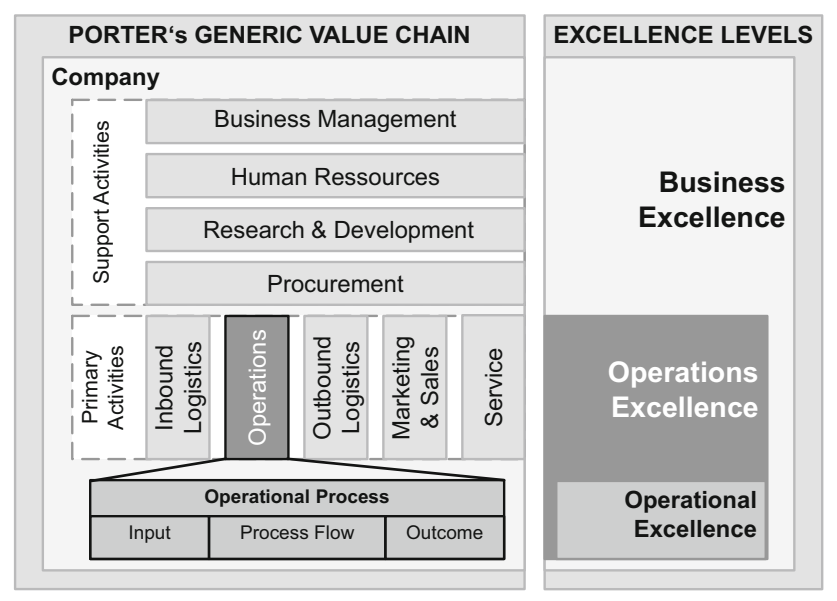

Fig. 1 Difference of business, operations and operational excellence, based on Porter [3]
The historical basis of operational excellence and operations excellence is anchored in a stream of literature dealing with the pioneering approach of production optimization. But at that time, researchers did not explicitly express the terms OE or OsE. Smith's output maximization of production processes and labor specialization, Ford's assembly line process development as well as Taylor's efficiency movement and scientific management aimed at an organizational setup to produce efficiency and increase productivity [7]. In addition, the philosophies and operation techniques of Eli Whitney, W. Edwards Deming, Joseph Juran, Philip Crosby, and Arnold Feigenbaum [8, 9] made supplementary contributions to the formation of $\mathrm{OE}$ 1.0 .

As the terms $\mathrm{OE}$ and also OsE per se are neither meaningful nor directly measureable, they have to be operationalized. In the phase of operationalization, theoretical concepts (here $\mathrm{OE}$ and $\mathrm{OsE}$ ) are translated into entities that can be observed or measured in the practice by empirical research [10]. By filtering propositions from individual authors' interpretations of OE or OsE from literature, a maximum of eight attributes (variables, terms of measurements, and indicators) were identified and counted for each evolution stream of OE 2.0, OE 3.0 and $\mathrm{OE} 4.0$ (Table 1).

Porter [3, 31], and Treacy and Wiersema [11] developed the OE's 2.0 price-oriented perspective. It declares that companies who pursue OE 2.0 operate at lower costs than their competitors, allowing them to deliver goods and services to their customers at lower prices and better value.

Brookbanks et al. [20] examine that operational excellence aims to maximize operational resilience through efficient and flexible integrated management and production processes. The approach of OE 3.0 is equivalent to the ambition of process reengineering and optimization as well as the usage of a classic production system containing philosophies of lean management, TQM, six sigma, etc. combined with consensus on the importance of customer orientation and the necessity of continuous improvement (CI). Although the utilization of Kaizen (PDCA) and the elimination of waste are often considered to be the main goals of operational excellence, they are only tools and activities to achieve it [32].

Gleich and Sauter [26] described an enabler-oriented framework in the context of OE 4.0 focusing the development, composition and expansion of enablers for continuous improvement, change, and the optimization of business processes. They present six fields they identified as essential for long-term operational success: strategy, operational and organizational structure, performance management, competences and skills, culture and leadership, systems and IT. Schwientek and Schmidt [27] as well as Sutton [30] offered a similar approach. They are among 


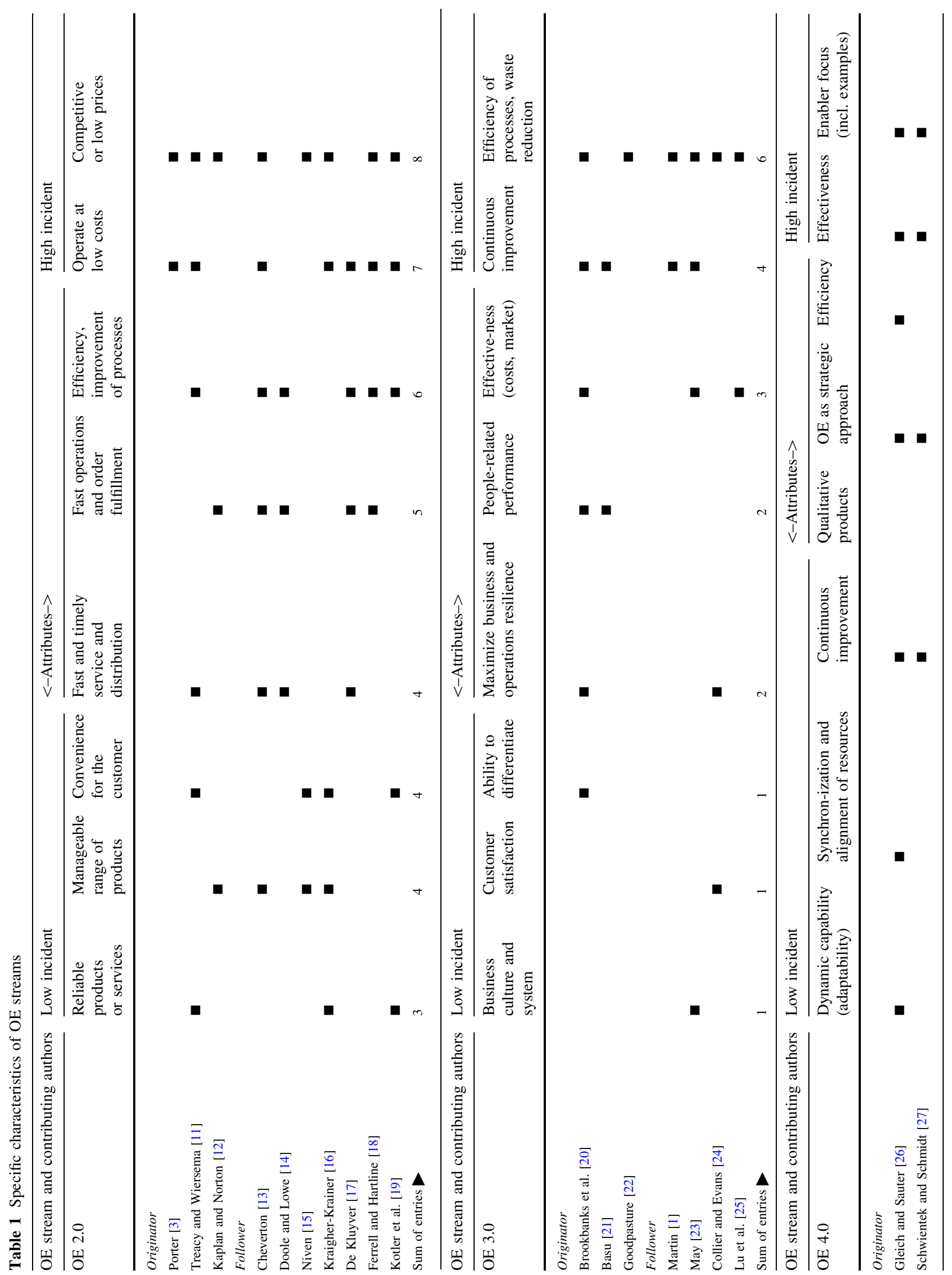




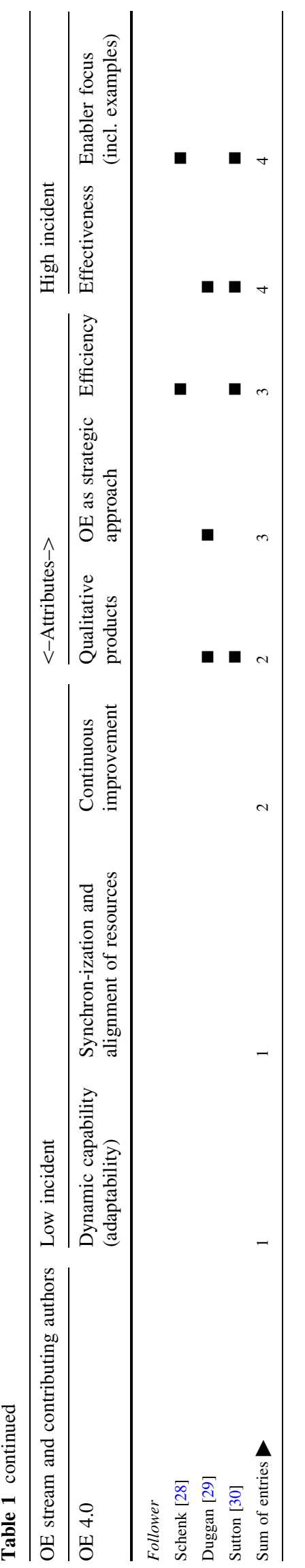

the few authors who elaborate on the term operations Excellence (OsE) by promoting operational enablers as central to operational success.

In Jaeger et al. [33] first ideas about the further development of the OE 4.0 interpretation are examined. A definition can be found in the following Sect. 3 and a concretion of relevant enabler and result criteria in Sect. 5 .

\section{Development of an OsE 1.0 working definition}

For the underlying research, existing OE 4.0 approaches cited in Sect. 2 have contributed substantially to the development of the following working definition of OsE 1.0. By adopting selected perspectives from referred authors and considering interactions of enablers and results, the following working definition of OsE 1.0 has been developed by the authors of the present research:

The philosophy of operations excellence is a management approach based on the continuous pursuit of creating a superordinated, agile system as a setting lever aimed at the maximization of the operations ability to identify and provide the adequate and optimal setting of enablers that are brought into alignment down and across the business strategy to gain sustainable, customer-driven results at the process level over the entire value chain. In the setting of enablers, particularly but not only intangible criteria such as culture, strategy, development, and empowerment are considered.

OsE 1.0 considers operational effectiveness before efficiency. It assumes that operations should first provide essential value to stakeholders' needs and then work towards being more efficient. The traditional belief is that excellence can be assessed through a series of metrics with certain parameters. However, OsE refers to an integrated approach toward performance management at the operations level, which results in the delivery of ever-improving value to customers and stakeholders. This also contributes toward sustainability, improvement of overall effectiveness, and capabilities and personal learning. Thus, the term "OsE 1.0" does not express an absolute superlative or preeminent condition. Instead, it describes the relation to comparatively weaker or more superior accomplishments, especially in comparison with oneself. The ability to pay attention and to balance excellence is one of the major obstacles to surpass and a task in which to excel. Therefore, further research elaborates on the evaluation of operations excellence. 
Fig. 2 EFQM excellence model [39]

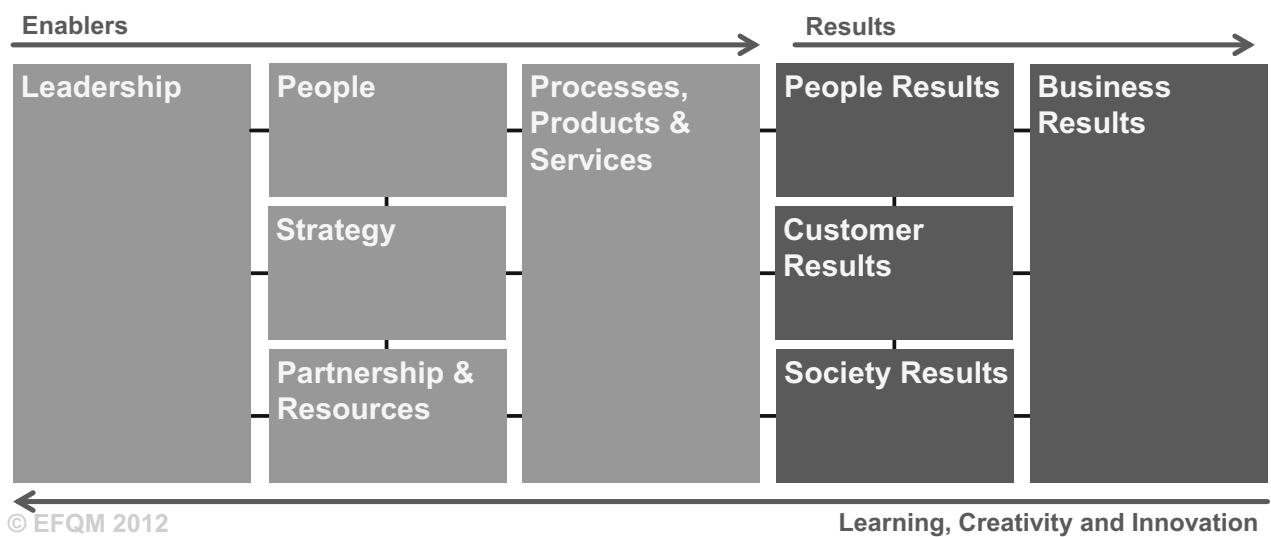

\section{The EFQM model for business excellence as fundamental basis for assessing operations excellence}

The European Foundation for Quality Management (EFQM) provides a well-founded business excellence model for self-assessment (Fig. 2). The model is globally accepted by both academics and industry [34]. Neither the EFQM model nor other excellence models are scientifically verified. However, there are strong indications that the EFQM model has a positive economic impact as it strengthens a company's competitiveness [35-37]. The EFQM recommends that organizations conduct selfassessment as a strategy to improve their overall efficiency [38].

However, the application of EFQM ratings, especially in terms of transferring its approach to OsE, poses four major challenges for companies, particularly small and mediumsized enterprises (SMEs):

1. Definition: For many organizations, the definition and interpretation of business excellence $[40,41]$ as well as the transfer to excellence in operations [42, 43] is too abstract. Hence, there is a need to develop an OsE model framework and terminology on the basis of the interpretation of the EFQM model.

2. Transparency: The EFQM model includes various enablers and results that are effectively linked to each other [44, 45]. The link of the cause-effect logic between specific enablers and results is however not explicitly drawn. Therefore, it is necessary to adapt the concept of assessment in a manner that makes transparent the cause-effect relationships of EFQM global organizational indicators with operations as well as their interdependencies with adjacent fields of OsE.

3. Application and usability: A lot of effort is needed for assessment preparation [46] and execution. "No explicit methods for successful implementation exist (...) and research should concentrate on how to implement strategic performance frameworks, i.e., the EFQM Excellence Model, effectively in specific types of organizations." [34]. Consequently, there is a clear need for a unified, simplified, and user-optimised EFQM assessment structure and process to evaluate OsE.

4. Prioritization of potentials: After the self-assessment's execution, the EFQM model does not offer any specific guidelines on the second phase, i.e., problem identification or potential formulation, nor does it indicate best or preferred practices [6]. In fact, it offers no structured approach to exploit strengths or classify and prioritize areas of improvement for the future [47, 48]. Experts, e.g., Richey [49], believe that assessors conducting a review of a company's excellence should be able to add specific suggestions that can be easily implemented.

Following, the research prescribes a two-stage modeling process:

- Step 1 (addresses challenge 1 and 2): Definition of an EFQM based OsE model framework with a clear illustration of criteria interdependencies. Section 5 of this paper targets these key issues.

- Step 2 (addresses challenge 3 and 4): Setting up of a supervised self-assessment of operations excellence (OsE SSA) to provide a methodology for an efficient application of EFQM on operations level. Section 6 addresses the design of the systematic assessment.

\section{Transfer of the EFQM approach to operations level}

Section 2 looked at the numerous overviews of OE perspectives as well as the limited number of OsE approaches that can be found in the literature. Since each interpretation has a different focus, a new agglomerated overview 
Fig. 3 OsE 1.0 model framework

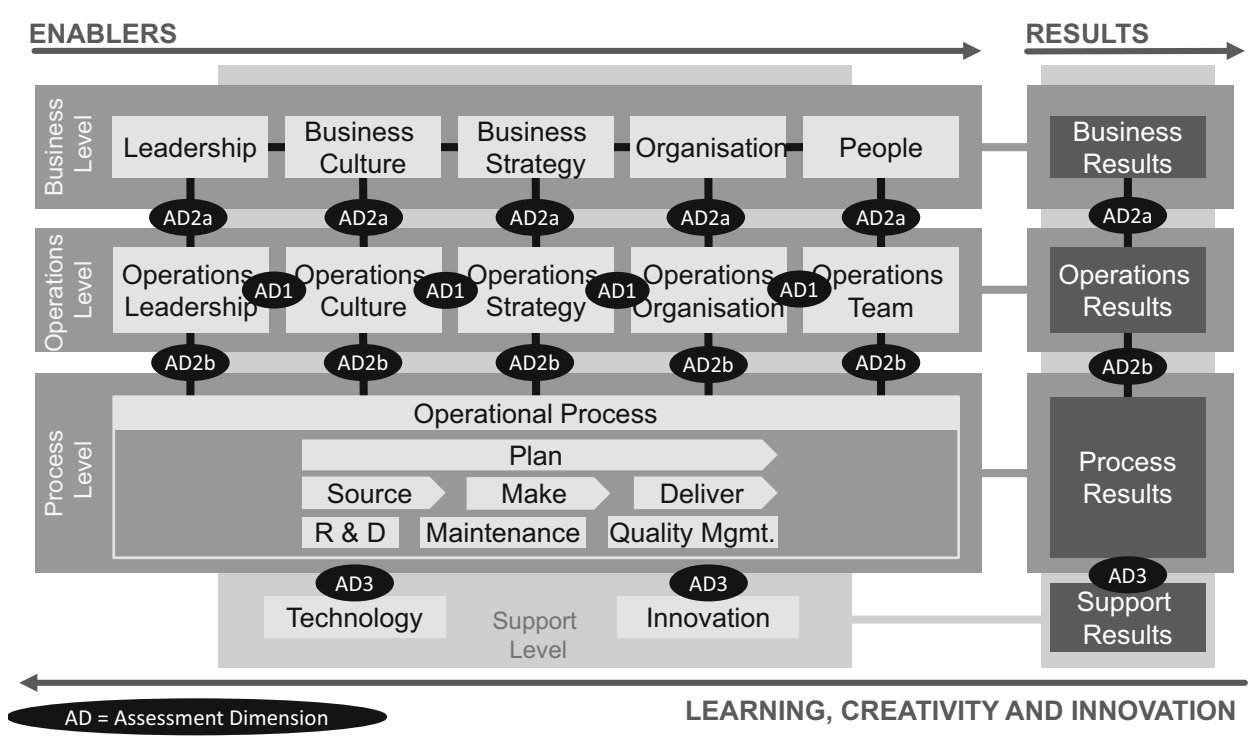

(Fig. 3) has been devised to be used as a more substantive basis for developing an assessment of OsE. The contextoriented and purposeful determination and specification of criteria relates to: (1) the findings of existing $\mathrm{OE} 4.0$ approaches in Sect. 2 and (2) the EFQM model in Sect. 4. Both approaches support the process of building theory through the consolidation of similar perspectives at the same scope based on practical experience. This inductive reasoning allows the creation of a rational and verifiable model framework.

The OsE 1.0 model framework represents a generic architecture for describing multiple enabler and result criteria, and the embedded chain of cause-effect logic to be assessed through various defined assessment dimensions (AD). Enabler criteria are regarded as drivers that positively influence other enablers or related results, while result criteria represent achieved effects through the promotion of enablers and the prevention of inhibitors [50, $51]$.

\subsection{Characteristics of OsE enabler and result criteria}

The OsE 1.0 framework can be divided into four main levels: business, operations, process, and support. Each level contains interlinked enabler and result criteria that in turn are connected to enablers and results from the other levels.

The "business level" is designed according to the EFQM Excellence model (Fig. 2). Minor changes can be found in the constellation and denotation of the criteria. For example, the OsE 1.0 framework determines "business culture" as a stand-alone criterion, whereas the EFQM model subordinates it to the criterion "leadership." The
EFQM enabler "partnerships and resources" was transformed into OsE 1.0 criterion "operations organization," but still represents a part of it.

The "operations level" transfers the enabler criteria from the business level to the operations level. The criteria are characterized, but not restricted, as the following:

Operations leadership relates to the middle management of production and logistics that design and improve structures, standards, and discipline. Leaders assume the role of coach and mentor by fostering motivation, inspiration, commitment, and recognition. Key responsibilities are the targeted planning, monitoring, and controlling of ongoing activities and the setting of appropriate strategic and dayto-day decisions. Leaders on the operations level are positioned in the center of the information cascade. Thus, they are required to communicate top-down to the shop floor with the support of control loops, and report bottomup to the management.

Operations culture addresses the establishment and deployment of production and logistics policies for pursuing continuous improvement through critical self-reflection. The strict orientation toward creating added value aims to reduce product and process complexity, and allows an open-error culture. The challenge that operations culture faces is that customer value is the central focus of production activities.

Operations strategy guides operations toward achieving its objectives through designing value chains and capabilities. Long-term objectives have priority and require renunciation of short-term benefits. The process of policy deployment can be supported through cross-functional action plans, roadmaps, and scorecards.

Operations organization addresses a proper environment on the operations level in order to promote beneficial 
activities for designing and improving key work processes, for adapting work systems, and for planning and managing external partnerships, suppliers, and internal resources.

Operations team refers to the development and empowerment of employees and shop-floor workers as well as the maximization of their knowledge, competencies, and contributions.

The "process level" focuses on "source" (procurement management, supply chain management, inventory management), continues with "make" (production logistics, manufacturing, and assembly), and ends with "deliver" (distribution and transport management). Furthermore, order processing, production planning, engineering, maintenance, and quality management are considered.

The "support level" deals with how innovation and technology management (TIM) contributes to optimizing operations' enablers and results. In fact, "innovation is no result but an enabler of an organization" [52], which indicates that the crucial influence of TIM on OsE has to be evaluated.

The group of results contains key performance indicators related to desired targets from individual levels, such as productivity, quality, delivery accuracy, or resource utilization on the process level. Business performance, as opposed to operational performance, is primarily concerned with financial and market results. The results of the operations level measure if adequate enablers represent drivers for high performance that are in line with the strategic, customer-related, and workforce-focused goals of operations.

The delimitation of the criteria meets the challenge of fulfilling the purpose of the OsE 1.0 framework and assessment. The scope of the framework is relatively broad but succinct, as it considers activities of all operational units along the organization's value chain, from suppliers to end customers. It provides a multi-dimensional picture of operations and does not pick out a limited number of specific areas or processes in order to achieve a holistic assessment approach. Thereby, the "criterion problem" or "criteria dilemma" arises. It illustrates the difficulty of being able to precisely represent the assessment object-in this case OsE-with an appropriate and entire batch of criteria. In addition, the EFQM model is confronted with the fact "not to be complete" [52-54]. However, its useful configuration of enabler and result criteria $[55,56]$ and its relative success in application have already been proven $[34,46,48]$.

\subsection{Correlation of OsE enabler and result criteria}

The EFQM model is famous for its pioneering role in drawing correlations between enablers and results. In recent years, several scientific papers, e.g. [43, 44], have addressed this issue. As the OsE is based on the EFQM model, its framework design meets the challenge of identifying and reviewing the cause-effect relationships of enabler and result criteria, instead of measuring and evaluating them in isolation. One reason for this is that actions within enabler criteria impacts on result criteria [55]. If a result is improved because of the optimization of one or more enablers, a loop activates new potentials and synergy effects with other enablers [39]. Furthermore, there is the traditional misunderstanding that if every part of a company, taken separately and independently, improves its performance, the performance of the organization as a whole will necessarily be improved. But "the focus of managing must be on the interactions, not the actions of the parts" [57]. Having transparency of interrelations among enablers and results but achieving success in only one isolated area is not enough to achieve excellence [58]. Another reason is that the management of intangible resources (e.g., skills and competences) cannot be realized through traditional quantitative indicators. Instead, causeeffect relationships between tangible and non-tangible resources and their contribution to the company's success are crucial. The intangible indicators will be monitored on cause-effect relationships to prevent a unilateral view of business ratios and figures.

Thus, the OsE model framework (Fig. 3) explicitly illustrates cause-effect relationships, so called assessment dimensions (AD) that have to be evaluated if operations excellence is targeted [33]. AD1 refers to correlating enabler and results criteria within the operations level, $\mathrm{AD} 2 \mathrm{a}$ looks at interdependencies between enablers and results on business level and operations level, AD2b strengthen the critical evaluation of how operations enablers and their characteristics manages activities on process level and AD3 checks how operations and operational processes are supported by technology and innovation criteria.

\section{Design of the OsE 1.0 supervised self-assessment phase model}

The central value of assessment is to highlight the causeeffect chains that connect the areas of enablers and results at the different levels. Due to the "left-right"-cross diagnoses in the OsE 1.0 model framework (Fig. 3), enablers that have an important influence on the results can be recognized. Correspondingly, the "right-left"-cross diagnoses focus on the observation of results. The evaluation begins with the enablers affecting results at the same level. The diagnostic path ends when the roots of the problem were identified at the same level. But if at this level only symptoms appear and the cause goes beyond this level, the 


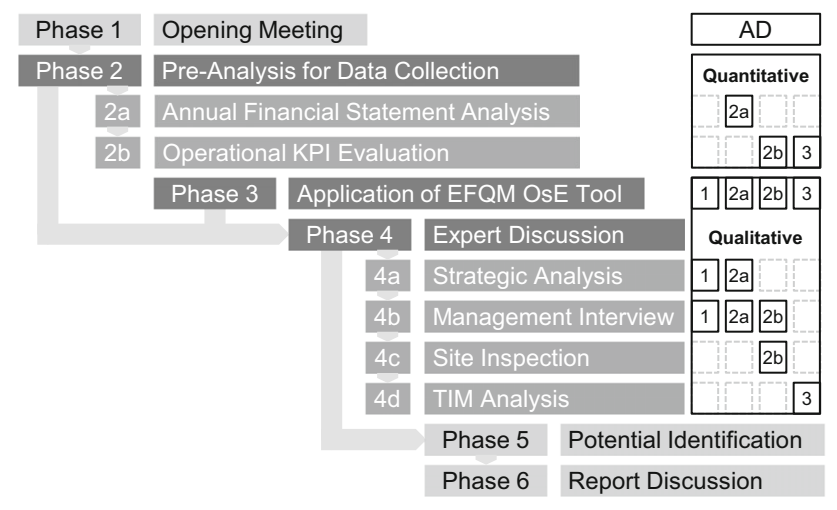

Fig. 4 Phase model for operations excellence supervised selfassessment

"top-bottom"- or "bottom-top"-cross diagnosis and consideration extends to a higher or lower level. These diagnoses direct the systematic inspection of the interdependencies of the enabler and result criteria on different levels.

To convert this approach, an assessment phase model (Fig. 4) was developed. It describes the structure and proceeding consisting of six phases that should be executed in a defined sequence, since the output data of one phase serves as input for the next. The subsequent phase, in turn, amplifies and verifies the previous phase. Each phase contributes by evaluating at least one assessment dimension as defined in Sect. 5.2. The value of the developed procedure is the integration of various evaluation methodologies to capture enablers and results from different perspectives.

\section{(1) Opening meeting}

The first phase involves the setting up of the assessment prerequisites and explanation of OsE's enabler-based approach, the OsE 1.0 model framework and the working definition. To create an understanding that ensures the organization takes advantage of the benefits provided by the assessment, common assessment objectives are defined. Objective (1) indicates the "Identification of operations enabler and result criteria, particularly the relationships responsible for creating customer value, and thus subsequently represent critical success factors." Objective (2) specifies the "Definition of challenges affected by the pursuit of the improvement of the relevant setting of enablers and the formulation of potentials aimed at its maximization and the related results." Finally, participants of the planned OsE SSA are identified and their roles and responsibilities are determined.

(2) Pre-analysis for data collection

The pre-analysis phase involves financial analysis and nonfinancial analysis. If the necessary information can be extracted from existing data, this will significantly reduce the effort needed for data collection.

\section{(2a) Annual financial statement analysis}

The basis of this economic analysis refers to the approach of "Operations Due Diligence" [59] based on the profit and loss account and the balance sheet. This analysis aims to identify cost drivers of production and logistics and related business enablers with the support of analyzing sample receivables, payables, inventory, and assets. Furthermore, investment behavior can be checked (Table 2)[60-62]

\section{(2b) Operational KPI evaluation}

There exist different performance measurement approaches to evaluate manufacturing and logistics via metrics [63-66]. In terms of the OsE SSA, the basis for this phase is a standardized KPI evaluation form with 72 predefined metrics. In most cases, absolute values (e.g., lead time, sum of training days or maintenance costs) cannot provide useful information, hence trends (e.g., export history, changing degree of automation, decrease of energy costs) are analyzed and relative values (e.g., delivery reliability, maintenance cost structure, ratio of training costs per employee in comparison to turnover, reject rate, etc.) are determined according to a standardized calculation formula. Obtained data is used for benchmarking participating companies as well as to interpret company-specific results. The assessors do not rate the individual KPI results but rather request companies to use the "metrics as a guide for self-assessment and develop their own definitions of poor, adequate, good, or excellent" [67]. This allows an interpretation of how selected measures are affected by key enablers at the process level and operations level (according to assessment dimension “AD 2b").

\section{(3) Application of EFQM-based OsE tool}

The operations excellence self-assessment software tool is anchored in the online assessment tool Group Opinion Analyzer (GOA), which is consistent with, and accepted by, EFQM. It is structured according to the enabler and result criteria from the OsE 1.0 model framework. Each criterion provides a set of questions or statements that have to be evaluated by the respondent on two pre-defined maturity scales from 0 to $100 \%$. The maturity scale 1 supports the evaluation of the current situation: $0 \%$-nonsatisfying; $25 \%$-below average; $50 \%$-average; $75 \%$-good; $100 \%$-outstanding. If $75 \%$ or more is chosen, the respondent has to provide evidence for his or her rating. The maturity scale 2 is used for the evaluation of the need for improvement: $0 \%$-no action needed; $20 \%$-probable need for action; $40 \%$-low need for action; $60 \%$-need for action; $80 \%$-high need for action; $100 \%$-very high need for action. If $40 \%$ or more 
Table 2 Examples of financial KPIs for production and logistics analysis [60-62]

\begin{tabular}{|c|c|c|c|c|c|c|c|}
\hline Analysis of & Assets & KPI example & Investment intensity & Analysis of & Assets & KPI example & Stock turnover period \\
\hline Investment ir & ity (in & $\frac{\text { capital a }}{\text { balance } \mathrm{s}}$ & & \multicolumn{4}{|c|}{ Stock turnover period (in days) $=\frac{\text { average inventory } * 365}{\text { cost of materials }}$} \\
\hline $\begin{array}{l}\text { High asset in } \\
\text { machinery. } \\
\text { high fixed } \\
\text { adapt to the } \\
\text { lasting inve } \\
\text { large lease }\end{array}$ & $\begin{array}{l}\text { ity ma } \\
\text { h inten } \\
\text {. Enter } \\
\text { e of en } \\
\text { ent stor } \\
\text { mitme }\end{array}$ & $\begin{array}{l}\text { lue to new p } \\
\text { dicates capi } \\
\text { do not usua } \\
\text { ment. Low in }\end{array}$ & $\begin{array}{l}\text { tion equipment or } \\
\text { tensive processes and } \\
\text { ave the flexibility to } \\
\text { ty may be due to long- } \\
\text { oduction facilities or a }\end{array}$ & \multicolumn{4}{|c|}{$\begin{array}{l}\text { The stock turnover period expresses the hypothetical dwell time of } \\
\text { inventories in the company. A distinction is made between raw } \\
\text { materials and consumables, as well as between semi-finished and } \\
\text { finished goods. Basically, a high turnover rate is desirable. Low } \\
\text { performance on this measure could indicate difficulties in sales. The } \\
\text { shorter the stock period, the shorter the capital lockup due to storage } \\
\text { costs }\end{array}$} \\
\hline
\end{tabular}

Analysis of Cost structure KPI example Material intensity
Material intensity (in $\%)=\frac{\text { material costs*100 }}{\text { capital costs }}$
Material intensity shows the extent to which the company has
materials and other external services used for the production of
goods. A particularly high rate of more than 50\% is an indication
that many components are purchased from third-party producers. A
low material intensity suggests increased in-house production. The
vertical range of manufacture can thus be estimated. Rising or falling
material intensities may result from, for example, personnel changes,
increased automation, optimized logistics and stock structures, or
improved purchasing sources

Analysis of Cost structure KPI example Personnel intensity

Labor intensity (in $\%)=\frac{\text { wages and salaries*100 }}{\text { capital costs }}$

Labor intensity indicates the share of personnel costs for the provision of services. The amount of manual work to produce goods, the degree of production automation, and the volume of sub-contracted fabrication influence this KPI, and should be scrutinized by SMEs. Wages and salaries are one of the largest cost types for a company and are, if necessary, rapidly degradable. Weak profitability often results from high labor costs

is chosen, the respondent can provide his or her primary ideas for potential improvement actions.

Members of the company can implement the assessment without any help. The most valuable result of the tool application is the preparation of participants to deal "with the complexity and for probing the relationship between cause and effect (enablers and result), using self-assessment" [68] and to identify potentials that can be discussed in detail in the later phases. External assessors can then reach a conclusion about how companies are able to reflect on their current situation and any need for action. The maturity of the individual SME's change culture can then be observed.

\section{(4) Expert discussion}

This phase involves a three-day workshop at each production company, and includes an empirical assessment with a methodical questionnaire, a systematic discussion, and a site inspection with quantitative and qualitative data as a results.

External experts face the challenge of appropriately conveying the approach of OsE 1.0 by adopting several enabler and result criteria according to the requirements of the individual organizations. With the help of the project team, critical cause-effect chains have to be identified, and the alignment of affected criteria has to be checked.

\section{(4a) Strategic analysis}

The strategy evaluation consists of a structural, causality, and strategy development analysis. The structural analysis is used to explore the operations strategy's contents and to determine what types of elements (e.g. configuration of the production system, location decisions, product characteristics, process technology, work force, and job design, etc.), are essential and if they are consistent [69, 70]. The causality analysis proves, according to the assessment dimension AD2a, whether the company's operations strategy is derived from its business strategy and in turn, whether its operations strategy and activities can confirm their bottom-up contribution to, and consistency with, the organization's business strategy and its linkage to the plant's overall goals. "Excellence in operations is about how the operations side of the business supports business growth as a strategic part of business." [29]. The strategy development analysis evaluates the SME's strategic planning and development process, including phases of strategy formulation and adaption, implementation, and control. The central question here is how companies systematically identify customer requirements, new technologies, competitors, and market trends, and how they assimilate the information into their business as well as their operations strategy, through the definition of objectives, deployment of long-term action plans, i.e., road maps, and adequate measures at the operations and process levels.

The strategic analysis is supported by the application of different methodical approaches, e.g., the PEST (political, economic, social, technological) analysis or the SWOT (strengths, weaknesses, opportunities, threats) analysis that enables managers to better understand and respond to strategic issues that have the greatest importance for the organization's performance. 


\section{(4b) Management interview}

The methodical focus on the interview as a key diagnostic tool is well established, even if the possibility of methodical one-sidedness exists. The high elasticity of the interview process, with its very flexible application opportunities and its wide acceptance by leaders, is the reason for its particular importance. The OsE SSA interview is directed by a standardized questionnaire, including checklists. Both elements are flexible and can easily be adapted to the individual company. For subsequent potential deduction, data are gathered through discussions with the organization's managers, particularly those responsible for operations, production, logistics, and supply chain management.

The management interview utilizes a procedure that follows the OsE 1.0 model framework with the assessment dimensions presented in Fig. 3. It is divided into three modules. The first module covers the enabler criteria "operations leadership", "operations culture", “operations strategy", "operations organization" and "operations team", and their interaction (AD1). Accordingly, correlations with similar issues at the business level are also examined (AD2a). The third module is concerned with the process level and its elements "plan", "source", "make" and "deliver", as well as "R\&D", "maintenance", and "quality management". Parallel to the discussion of process results, correlating enablers at the operations level are scrutinized (AD2b).

In all three modules, the respondents have to provide three different views: (V1) current state: "as-is" view; (V2) planned state and related activities: "to-be" view; (V3) desired ideal state: "best case" view. Past and due daterelated information (V1) serve as an orienting basis for predicting future developments (V2) and for making plausibility checks of desired targets (V3). The status of current activities (V1) is evaluated according to the transformation philosophy of "Plan-Do-Check-Act" (PDCACycle) developed by Deming [71] by critically scrutinizing if certain enablers, behaviors, and procedures are only planned, already available or almost optimized towards a desired maturity level.

\section{(4c) Site inspection}

The site inspection of the OsE SSA is based on the philosophy of the gemba walk to "look at the processes" [72] directly at the plant or selected production facilities. "Gemba" is translated to mean "the actual spot where action takes place" or "the real place where value is created" [73]. For the assessors the site inspection offers the opportunity to talk and listen directly to those on the shop floor. Problems can be viewed directly and working behavior can be observed. Suggestions and feedback from, e.g., machine operators, must be accepted and evaluated without any initial reaction in order to resolve the dilemma that shop floor workers may feel uncomfortable being observed by assessors, which could impair the establishment of an open and constructive dialog between the two parties. With operations management the discussions can include segmentation and layout of manufacturing systems, assembly lines, and logistic spaces. Furthermore, state-of-theart production technology, e.g., machinery and technical equipment, and related aspects, such as maintenance, can be observed.

Site inspection provides valuable insight into how operations culture and strategy is conveyed from the management to the shop floor and vice versa, i.e., how the execution of processes contributes to operations performance (AD2b).

\section{(4d) Technology and Innovation self-assessment}

To operationalize AD3 and determine how technology and innovation management (TIM) supports business, operations, and process objectives, a TIM self-assessment model was developed based on the research of Abele [74]. Its structure (Fig. 5) allows a systematic analysis of various TIM dimensions (from idea generation to innovation review) on the product level, production process level, and their interface. Guided by critical questions from external experts, workshop participants have to rate the current state for each cross-linking evaluation field by themselves in a team consensus. Thereby, they have three evaluation options: (1) satisfactorily implemented; (2) initiative started; or (3) urgent need for improvement.
Fig. 5 TIM-self-assessment model (modelled after Abele [74])

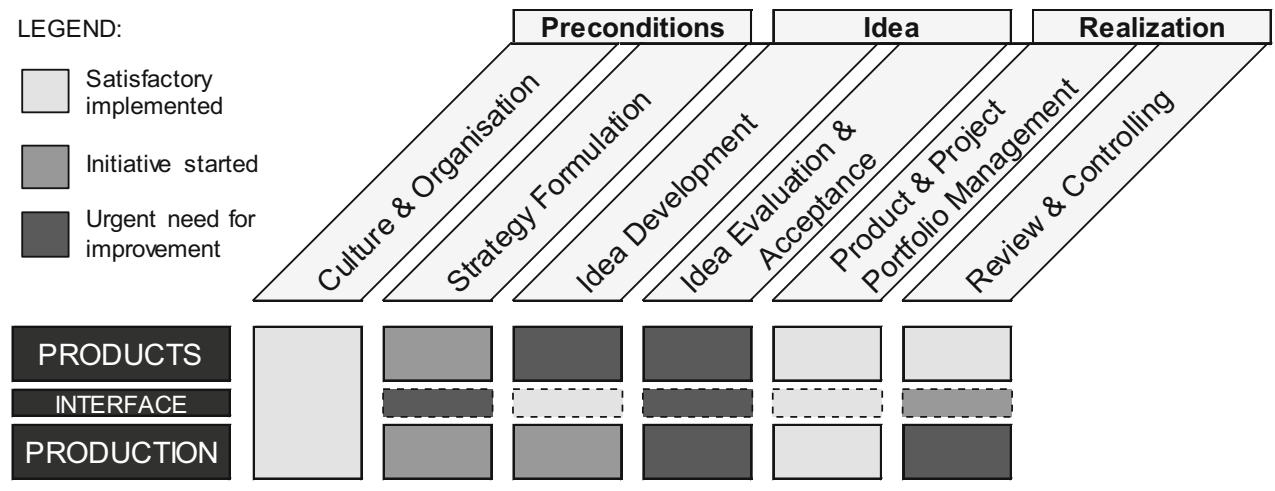


The assessment determines the effective use of enablers such as innovation strategy, resources, technological capabilities, market expertise, or knowledge management for planning and realizing the innovation process. Results such as "time to market" or "success rates" of past innovation projects help to identify how efficient ideas result in valuable products or process innovation, and thus additional customer value.

\section{(5) Potentials identification}

The conclusion of the assessment is the identification of potentials based on a benchmark analysis [75, 76]. Benchmarking is defined as the process of comparing and measuring one organization against others to gain information about philosophies, practices, and measures that will help the observed organization take action to improve its performance. "Benchmarking is the practice of being humble enough to admit that others are better at something and being wise enough to learn how to match, and even surpass them" [77]. Since data from several companies are gathered during the OsE supervised self-assessment process, the necessary information is obtained to not only measure a company's performance but also compare it with that of other selected companies. The companies participating in the OsE SSA were benchmarked against each other as well as against best-in-class manufacturers consisting of companies from various awards presenting best practices.

Thus, phase 5 forces a depiction of the present situation as well as how it deviates from benchmarks [48]. Then, potentials for companies' performance improvement can be identified.

\section{(6) Report discussion}

Once the assessment has been conducted, the company carries out through action plans, a performance improvement process in line with the organization's strategy. Thus, findings from phase 5 are documented in a report that is discussed in a feedback session. Based on recommended potentials, the project team identifies specific actions and organizes them into a priority list. By allocating relevant resources and time horizons, an action plan is created. The action plan development constitutes the final but critical stage in planning to avoid that SMEs make intuitive decisions without the help of control instruments.

\section{Case studies and verification}

For verification, the authors of this paper discuss a set of case studies that show how successfully the developed philosophy of OsE can be conveyed at assessed companies. Case studies present an appropriate methodological means to discuss such a complex construct as the enabler-based assessment methodology of OsE, despite some experts' claims that they face difficulties in terms of providing general guidelines. Nevertheless, case studies are very valuable in explaining superior management in a very detailed manner. Rather than presenting these case studies in detail, observations and results from the application of the OSE SSA are discussed instead. Here the authors of this paper refer to recent literature contributing to best practices in OE and OsE, e.g., Gleich and Sauter [26] and Loch et al. [78]. Thus, the focus of the case studies is the transfer of the OsE 1.0 approach and its assessment.

After a piloting test phase with three selected companies, the OsE SSA was rolled out in the machine and metalware industries in Austria. At the time of writing this paper, 24 SMEs (10 equipment manufacturers, 14 batch manufacturers) from these industries have participated, and more SMEs will be added in the future. The key findings arising from the empirical research are summarized as follows.

\subsection{Statistical examination of external assessors}

Upon executing the OsE SSA, external evaluators rated the individual SME's readiness for applying OsE through continuous efforts and measures. Figure 6 shows the resulting classification of participating companies into five groups. In industrial practice, the majority of equipment manufacturers still associate the term "excellence in operations" with $\mathrm{OE}$ 2.0, which promotes cost minimization. Batch manufacturers prevail in OE 3.0 by focusing on process optimization activities. Only a few companies already practice or tend to deal with enablers, results, and their interconnections in particular, as they strive towards OE 4.0/OsE 1.0.

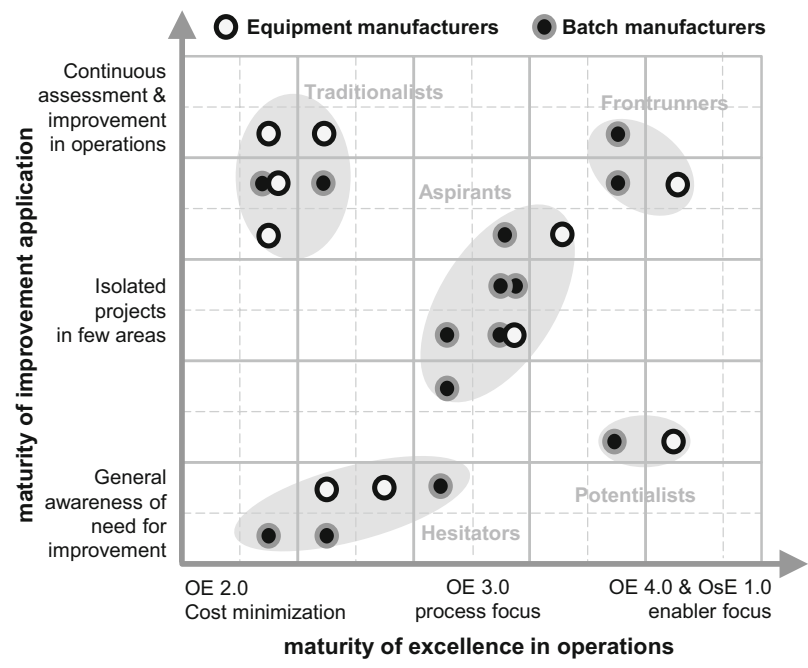

Fig. 6 Classification of 24 assessed companies 


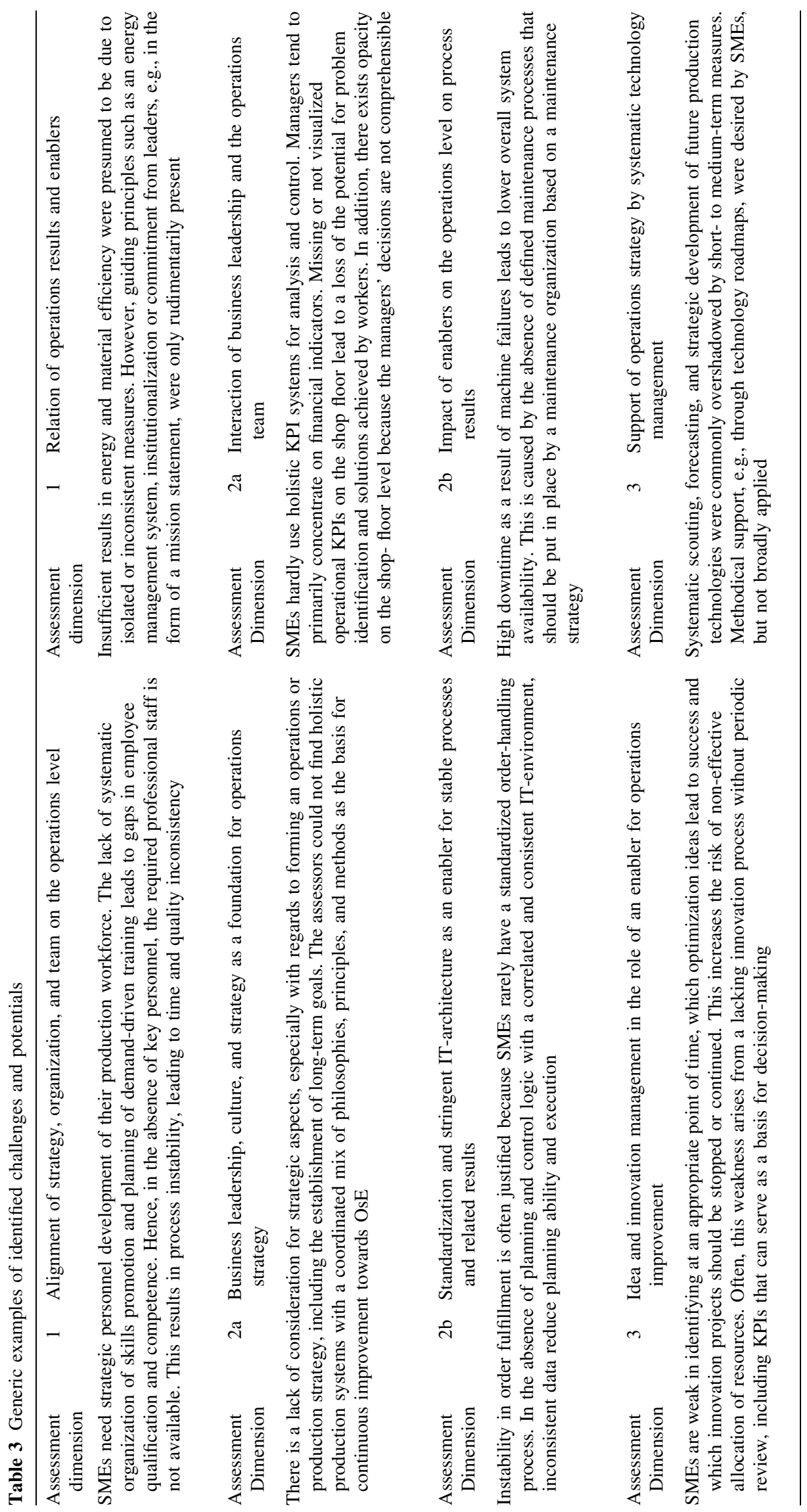


It was predominantly observed that there were commonly isolated projects and solutions in individual departments or processes with limited considerations of other affected areas. Less frequent were integrative and comprehensive improvement initiatives based on defined models or frameworks including self-assessment.

\subsection{Examination of assessment results}

As previously mentioned, declared assessment dimensions (AD) supported the identification of challenges and potentials. Therefore, symptoms of weaknesses were traced back to the end of the chain of causes. Two most common examples for each assessment dimension are summarized as follows (Table 3).

\subsection{Feedback survey from participating companies}

To evaluate how applicable the OsE enabler-based assessment methodology is, a survey was conducted with three project team members of each of the 24 SMEs to collect individual feedback. The main objective was to compare their initial perception, discussed during the initial meeting (phase 1, Sect. 6), against the final outcome of the OsE SSA. The following findings on the OsE SSA's impact on assessed organizations were noted:

- Approx. $85 \%$ of respondents acknowledge the traceability of EFQM at the operations level through the OsE model framework 1.0 and related work definition.

- Approx. $90 \%$ agree that the OsE's enabler-embedded approach profoundly affects how results and their manipulating enablers are reflected. Thus, considerations of the developed assessment dimensions can advance the transparency of drivers to be optimized.

- Approx. $95 \%$ agree that the OsE SSA provides a structured process for potentials identification through its phase model, which assists a systematic quantitative, as well as qualitative, evaluation.

- Approx. $80 \%$ confirm that the OsE SSA allows, in a relatively short period of time, the identification of potentials toward OsE. For $5 \%$ however, the assessment took too much effort, particularly the pre-analysis for data collection (phase 2 in Sect. 6) which took between two to four man-days.

After a period of approximately 6-8 months, a second round of feedback was obtained through conversations with responsible persons from each company. Major assessment outcomes, especially the identified potentials and recommended actions, were discussed in retrospect. Companies also reported their ongoing activities regarding OsE. The discussions can be summarized as follows.
The introduced approach of OsE initially seemed very academic. However, the application of the OsE SSA contributed to a comprehensive and uniform understanding of OsE within the SMEs' project teams. A company interpretation of OsE was derived from debates with the external experts about theory, arguments from existing literature, empirical research, practical understanding, and industrial applicability.

OsE SSA provides a new impetus to start a companywide optimization initiative with a strategic and long-term perspective. After applying the OsE SSA, the project team faces the challenge of conveying the initiated mission of OsE company-wide, which is in effect, a demand for cultural change.

Considering the common developed action plan in phase 6 (Sect. 6), companies face the challenge of its realization, as, day-to-day business often seems to present a significant obstacle. Thus, there is the risk that SMEs do not benefit from ideas generated through the OsE SSA due to insufficient implementation.

\section{Conclusion}

The topic of excellence in operations has increasingly gained researchers' attention in recent decades, especially in the applied sciences. Various interpretations have been summarized to provide a significant insight into the trend development of excellence approaches across different research. It is particularly disconcerting that no widely accepted definition for the term operations excellence exists. A clearly formulated definition cannot be found in today's literature. This paper makes a contribution to the scientific discourse by providing a working definition for operations excellence (OsE 1.0) in Sect. 3, followed by the design of the OsE 1.0 model framework (Fig. 3) and the identification of enablers and results criteria. The supervised OsE SSA, provides a methodology (Sect. 6) for employing the approach of excellence in SMEs' operations through the operationalization of the assessment dimensions.

Limitations of the OsE SSA methodology include the fact that currently, information is directly captured only from the participating SMEs' management and employees. Data about external stakeholders such as shareholders, customers, competitors, investors, and suppliers are indirectly obtained via customer satisfaction surveys, market analysis, or supplier ratings. Thus, a better balance of information from internal and external respondents could improve the value of the OsE SSA.

The application of OsE SSA at SMEs in the machinery and metalware sector indicates that the majority of them need to readjust their focus toward systematic self- 
assessment and continuous identification of potentials. The case studies revealed that while problems can be easily discovered, their causes could be too diverse and complex to identify. However, determining the interdependencies between enablers and results constitutes the critical basis for successfully deriving company-specific sets of actions. By applying the OsE 1.0 assessment, companies benefit from its fundamental basis in the philosophy of EFQM which enjoys high acceptance and is verified through a high frequency of industrial application. Conveying the excellence approach from the business level to the operations level was the first step of extending its scope of application. Future research should concentrate on how excellence assessments could be vertically and horizontally integrated. Vertical integration should be achieved by conveying the excellence approach top-down from business and operations to personnel and personal excellence. While horizontal integration can be attained through sharing the approach with suppliers and customers in order to extend the assessment objective from separate companies to production networks. Then, new challenges with regards to assessment methodologies for data collection and processing will be discovered and will require solutions.

Acknowledgments Open access funding provided by TU Wien (TUW).

Open Access This article is distributed under the terms of the Creative Commons Attribution 4.0 International License (http://crea tivecommons.org/licenses/by/4.0/), which permits unrestricted use, distribution, and reproduction in any medium, provided you give appropriate credit to the original author(s) and the source, provide a link to the Creative Commons license, and indicate if changes were made.

\section{References}

1. Martin J (2007) Operational excellence: using six sigma to translate customer value through global supply chains. Auerbach, Leipzig

2. Porter LJ, Tanner SJ (2004) Assessing business excellence. Routledge, New York

3. Porter ME (1985) Competitive advantage: creating and sustaining superior performance. Free Press, New York

4. Wight $\mathrm{O}$ (2010) The Oliver Wight Class A checklist for business excellence. Oliver Wight International Inc., New Jersey

5. Lu D (2011) In pursuit of worldclass excellence. Ventus Publishing, Telluride

6. McAdam R, O'Neill E (1999) Taking a critical perspective to the European Business Excellence Model using a balanced scorecard approach: a case study in the service sector. Manag Serv Qual 9(3):191-197

7. Chang J (2006) Business process management systems-strategy and implementation. Auerbach Publications, Boca Raton

8. Nersesian R (2000) Trends and tools for operations management: an updated guide for executives and managers. Greenwood Publishing, Westport
9. Sinha P (2008) Manufacturing and operations management. Nirali Prakashan, Pune

10. Thiel S (2014) Research methods in public administration and public management. Routledge, Oxon

11. Treacy M, Wiersema F (1993) Customer intimacy and other value disciplines. Harv Bus Rev 71(1):84-93

12. Kaplan RS, Norton DP (2000) Having trouble with your strategy? Then map it. Harvard Business School Pub. Corp., Boston

13. Cheverton P (2004) Key marketing skills 2: strategies, tools and techniques for marketing success. Kogan Page, London

14. Doole I, Lowe R (2005) Strategic marketing decisions in global markets. Thomson Learning, London

15. Niven PR (2006) Balanced scorecard step-by-step: maximizing performance and maintaining results. Wiley, Hoboken

16. Kraigher-Krainer J (2007) Das ECID-Modell: Fünf Kaufentscheidungstypen als Grundlage der strategischen Unternehmensplanung. Gabler Verlag, Wiesbaden

17. De Kluyver C (2010) Fundamentals of global strategy: a business model approach. Business Expert Press, New York

18. Ferrell OC, Hartline MD (2011) Marketing strategy. Cengage Learning, Mason

19. Kotler P, Armstrong G, Wong V, Saunders J (2011) Grundlagen des Marketing. Pearson Studium, München

20. Brookbanks M, Gandy A, Pourquery P (2002) Operational resilience: the art of risk management. Financial World Publishing, Canterbury

21. Basu R (2004) Implementing quality: a practical guide to tools and techniques: enabling the power of operational excellence. Thomson Learning, London

22. Goodpasture JC (2004) Quantitative methods in project management. J. Ross Pub, Boca Raton

23. May C (2007) Operational Excellence: Mit Total Productive Management zu Weltklasseformat. Ind Inf Tech 102:479-483

24. Collier DA, Evans JR (2011) Operations management: A studenttested, faculty-approved approach to teaching and learning operations management. South-Western Cengage Learning, Ohio

25. Lu D, Betts A, Croom S (2011) Re-investigating business excellence: values, measures and a framework. Total Qual Manag Bus Excell 22:1263-1276

26. Gleich R, Sauter R (2008) Operational Excellence: Innovative Ansätze und Best Practices in der produzierenden Industrie. Rudolf Haufe Verlag, München

27. Schwientek R, Schmidt A (2008) Operations excellence: Smart solutions for business success. Palgrave Macmillan, New York

28. Schenk M (2010) Kooperation im Anlagenbau-Operational Excellence im Anlagenbau. 12. Industriearbeitskreis. Fraunhofer Verlag, Stuttgart

29. Duggan KJ (2011) Design for operational excellence: a breakthrough strategy for business growth. McGraw-Hill Professional, Columbus

30. Sutton D (2012) Back to basics: a practitioner's guide to operations excellence. Operations Excellence Services, Cincinnati

31. Porter ME (1996) What is strategy? Harv Bus Rev 74(6):62-78

32. Miller RD, Raymer J, Cook R, Barker S (2013) The Shingo model for operational excellence. Logan, Utah

33. Jaeger A, Matyas K, Sihn W (2014) Development of an assessment framework for operations excellence (OsE), based on the paradigm change in operational excellence (OE). Proced CIRP 17:487-492

34. Wongrassamee S, Gardiner P, Simmons J (2003) Performance measurement tools: the Balanced Scorecard and the EFQM Excellence Model. Meas Bus Excell 7:14-29

35. Gavrila C, Caulkins JP, Feichtinger G, Tragler G, Hartl RF (2005) Managing the reputation of an award to motivate performance. Math Methods Oper Res 61:1-22 
36. Hertz H (2012) The impact of Baldrige on organizational performance. J Qual Particip 35:4-7

37. Jacob R, Madu C, Tang C (2004) An empirical assessment of the financial performance of Malcom Baldrige Award winners. Int $\mathrm{J}$ Qual Reliab Manag 1:897-914

38. Hakes C (2007) The EFQM Excellence Model for assessing organizational performance. Van Haren Publishing, Amersfoort

39. EFQM (2012) EFQM excellence model, Brussels

40. Hughes A, Halsall DN (2002) Comparison of the 14 deadly diseases and the business excellence model. Tot Qual Manag 13:255-263

41. Sandbrook M (2001) Using the EFQM Excellence Model as a framework for improvement and change. J Change Manag 2:83-90

42. Estampe D, Lamouri S, Paris J, Brahim-Djelloul B (2010) A framework for analysing supply chain performance evaluation models. Int J Prod Econ 142:247-258

43. Gomez J, Costa M, Lorente A (2010) A critical evaluation of the EFQM model. Int J Qual Reliab Manag 28:484-502

44. Calvo de Mora A, Leal A, Roldan J (2005) Relationships between the EFQM model criteria: a study in Spanish universities. Total Qual Manag Bus Excell 16:741-770

45. Sadeh E, Arumugam V (2010) Interrelationships among EFQM excellence criteria in Iranian industrial SMEs. Eur J Econ Finance Adm Sci 19:155-167

46. Lee P, Quazi HA (2001) A methodology for developing a selfassessment tool to measure quality performance in organizations. Int J Qual Reliab Manag 18:118-141

47. Kanji GK (2001) Forces of excellence in Kanji's business excellence model. Total Qual Manag 12:259-272

48. Rusjan B (2005) Usefulness of the EFQM excellence model: theoretical explanation of some conceptual and methodological issues. Total Qual Manag Bus Excell 16:363-380

49. Richey D (1996) The Shingo Prize for excellence in manufacturing. J Qual Particip 19:28-30

50. Pagell M (2004) Understanding the factors that enable and inhibit the integration of operations, purchasing and logistics. J Oper Manag 22:459-487

51. Rich N, Bateman N (2003) Companies' perceptions of inhibitors and enablers for process improvement activities. Int J Oper Prod Manag 23:185-199

52. Leonard D, McAdam R (2002) The role of the business excellence model in operational and strategic decision making. Manag Decis 40(1):17-25

53. Garvin D (1991) How the Baldrige Award really works. Harv Bus Rev 69(1):80-93

54. Simms A, Bowles J, Crosbym P, Gale B, Garvin D (1992) Does the Baldrige Award really work? Harv Bus Rev 69(6):126-147

55. Bou-Llusar J, Escrig-Tena A, Roca-Puig V, Beltran-Martin I (2009) An empirical assessment of the EFQM Excellence Model: evaluation as a TQM framework relative to the MBNQA model. J Oper Manag 27:1-22

56. Russell S (2000) ISO 9000:2000 and the EFQM Excellence modelcompetition or co-operation? Tot Qual Manag 11:657-665

57. Roth W (2001) Moving beyond Baldrige: a call for a systems award for quality improvement. J Organ Excell 20:53-58
58. Naylor G (1999) Using the business excellence model to develop a strategy for a healthcare organization. Int J Heal Qual Care Assur 12:37-44

59. Grebey J (2012) Operations due diligence-An M\&A guide for investors and business. McGrawHill, New York

60. McLaney E, Atrill P (2005) Accounting-an introduction. Pearson Education Limited, Harlow

61. Pendlebury M, Groves R (2004) Company accounts-analysis, interpretation and understanding. Thomson, London

62. Proctor R (2009) Managerial accounting for business decisions. Pearson Education Limited, Harlow

63. Abdel-Maksoud A, Dugdale D, Luther R (2005) Nonfinancial performance measurement in manufacturing companies. $\mathrm{Br}$ Account Rev 37:261-297

64. Ahmad M, Dhafr N (2002) Establishing and improving manufacturing performance measures. Robot Comput Integr Manuf 18:171-176

65. Chen CC (2008) An objective-oriented and product line based manufacturing performance measurement. Int $\mathrm{J}$ Prod Econ $112: 380-390$

66. Hon K (2005) Performance and evaluation of manufacturing systems. CIRP Ann Manuf Technol 54:139-154

67. National Research Council (1996) World-class research and development: characteristics for an army research, development, and engineering organization. The National Academies Press, Washington

68. Finn M, Porter L (1994) TQM self-assessment in the UK. TQM Mag 2:56-61

69. Schmidt M, Joao E, Albrecht E (2005) Implementing strategic environmental assessment. Springer Verlag, Berlin

70. Telsang M (2006) Industrial engineering and production management. S. Chand \& Company Ltd., New Delhi

71. Urdhwareshe H (2011) Six sigma for business excellence: approach, tools and applications. Pearson, India

72. Mann D (2010) Creating a lean culture-tools to sustain lean conversions. CRC Press, Boca Raton

73. Protzman C, Mayzell G, Kerpchar J (2011) Leveraging Lean in healthcare-transforming your enterprise into a high quality patient care delivery system. Productivity Press, New York

74. Abele $\mathrm{T}$ (2013) Suchfeldbestimmung und Ideenbewertung. Springer Fachmedien, Wiesbaden

75. Campell D, Edgar D, Stonehouse G (2011) Business strategy—an introduction. Palgrave Macmillan, Hampshire

76. Watson G (2007) Strategic benchmarking reloaded with six sigma-improving your company's performance using global best practice. Wiley, New Jersey

77. Coers M, Gardner C, Raybourn C (2001) Benchmarking: a guide for your journey to best-practices processes. American Productivity and Quality Center, Texas

78. Loch C, Chick S, Huchzermeier A (2009) Managementqualität und Wettbewerbsfähigkeit: Was Manager vom Industrial Excellence Award lernen können. Springer, Berlin 